\title{
Editorial
}

\author{
Maria do Carmo Duarte Freitas ${ }^{1}$, Cristiane Sinimbu Sanchez ${ }^{2}$, Flávia Roberta Fernandes ${ }^{3}$ \\ 1 Universidade Federal do Paraná (UFPR), Curitiba, Paraná, Brasil. ORCID: http://orcid.org/0000-0002-7046-6020 \\ 2 Universidade Federal do Paraná (UFPR), Curitiba, Paraná, Brasil. ORCID: https://orcid.org/0000-0002-0247-3579 \\ 3 Universidade Federal do Paraná (UFPR), Curitiba, Paraná, Brasil. ORCID: https://orcid.org/0000-0002-1375-7091
}

Autor para correspondência/Mail to: Maria do Carmo Duarte Freitas, mcf@ufpr.br

Copyright (C) 2019 Freitas, Sanchez \& Fernandes. Todo o conteúdo da Revista (incluindo-se instruções, política editorial e modelos) está sob uma licença Creative Commons Atribuição-NãoComercial-Compartilhalgual 3.0 Não Adaptada. Ao serem publicados por esta Revista, os artigos são de livre uso em ambientes educacionais, de pesquisa e não comerciais, com atribuição de autoria obrigatória. Mais informações em http://revistas.ufpr.br/atoz/about/submissions\#copyrightNotice.

\section{A EMERGÊNCIA NA COMPREENSÃO DA “INFORMAÇÃO” PARA O AVANÇO DA CIÊNCIA}

O v8n2 da AtoZ apresenta seis artigos e cinco comunicações de pesquisa que, acompanhando o foco da revista, discutem a informação em seus distintos processos e facetas de análise, por meio de metodologias que trazem contribuições para a compreensão da informação como objeto de pesquisa.

Publicamos esta edição, vivenciando um cenário atípico, não obstante cíclico, em que nos vemos forçados a migrar, de uma hora para outra, para o ambiente digital de forma mais intensa, seja para nos inteirarmos do mundo, seja para continuarmos demonstrando afeto pelos que, assim como nós, estão enfrentando esta realidade tão desafiadora. Nesta conjuntura, ao buscar desvelar a complexidade das relações humanas com e para as redes de comunicação e informação, sejam estas virtuais ou presenciais, demonstra-se a importância e urgência do campo da ciência, gestão e tecnologia da informação.

Monica, Hack, Camacho e Pereira se preocupam em construir um portfólio bibliográfico sobre as transformações digitais, de modo a compreender como os avanços tecnológicos podem impactar e transformar as práticas de marketing e publicidade. A pesquisa de Molina e Santos aponta que organizações que pretendem se manter competitivas e inovadoras, devem fazer uso da gestão da informação para aproveitarem as oportunidades oferecidas pela $4^{\mathrm{a}}$ Revolução Industrial.

Buogo, Fachinelli e Giacomello, por meio da metodologia Delphi, concluem que há compatibilidade entre gerenciamento de conhecimento e segurança da informação para construção de um framework de gestão do conhecimento seguro. Ao buscar soluções para o possível aumento de produtividade, a otimização do tempo de atendimento e o compartilhamento do conhecimento em uma organização, Tôrres, Maia e Muylder indicam a utilização de um chatboot que consolida as possíveis soluções utilizadas anteriormente em uma organização. Em uma outra frente de pesquisa, o estudo de Neves se dedica a investigar os principais recursos utilizados por profissionais da informação - no caso investigado, os bibliotecários - na identificação e combate às Fake News em mídias sociais.

Santos, Oliveira, Freitas e Vieira apresentam os resultados da investigação no caso concreto da TV Universitária da Fundação Rádio e Televisão Universitária de Uberlândia (RTU), apoiadora da Universidade Federal de Uberlândia (UFU), mostrando que as TVs universitárias se tornar espaços de divulgação científica e jornalística para públicos cada vez mais heterogêneos.

As comunicações de pesquisa, deste número, reúnem as proposta apresentadas no último evento da Rede de Gestão da Informação e do Conhecimento - II Congresso de Gestão Estratégica da Informação, Empreendedorismo e Inovação (CGEI) que ocorreu, na Universidade Federal do Rio Grande do Sul (UFRGS), em Porto Alegre de 17 a 19 de junho de 2019.

Por meio de procedimentos de pesquisa bibliográfica e documental, as comunicações de pesquisa demonstram a emergência de discutir as contribuições da Gestão da Informação como estratégia viável para troca de informações entre academia e o campo de trabalho (Rocha \& Barbosa); de vislumbrar a Ciência da Informação como uma área interdisciplinar, voltada aos aspectos aplicados na gestão, organização e tecnologia da informação (Karpinski, Guerner \& Martins); e de evidenciar as redes de conhecimento na produção da comunicação científica (Stueber \& Teixeira).

Ao buscar identificar as potencialidades da utilização de um aplicativo de mensagens na gestão de atendimentos em uma empresa de manutenção de aeronaves, o estudo de Martins, Lopes e Ramalho apresenta, de forma mais pragmática, possibilidade de aplicação de tecnologias da informação e sua aplicação na melhoria da comunicação e direcionamento de recursos em uma organização. 
Martins e Rockembach, em pesquisa desenvolvida no âmbito da Universidade Federal do Rio Grande do Sul (UFRGS), discutem as possibilidades de arquivamento da web no âmbito acadêmico, concluindo que, entre outras considerações, as diferentes coleções da instituição preservam tanto a história organizacional de suas entidades, como também promovem o ensino, a pesquisa e a extensão de suas comunidades.

Com a publicação deste número também anunciamos a mudança no Comitê Editorial da Revista, apresentando a Profa. Dra. Maria do Carmo Duarte Freitas, vice coordenadora do Programa de Pós-Graduação em Gestão da Informação da UFPR, que agora assume a função de editora-chefe da AtoZ.

Saudamos aos leitores e avaliadores da Revista AtoZ! Acreditamos no poder da comunicação cientifica e na força que tem um periódico como "produto informacional" para aumentar a visibilidade das pesquisas científicas realizadas no país. Nós propomos a buscar a internacionalização deste periódico por meio das redes de parceria que temos na Europa e na América Latina. Além disso, manteremos o padrão de qualidade já certificado pelas bases que creditam e acolhem a Revista AtoZ. Aos autores deste número estimulamos que divulguem seus artigos nas redes sociais e nos sigam nos canais que usamos para divulgar sua pesquisa.

Agradecemos a colaboração do Prof. Dr. Glauco Menezes e temos boas expectativas de que a AtoZ continue contribuindo para o avanço das pesquisas em ciência, gestão e tecnologia da informação.

Boa leitura,

Os Editores

Curitiba, dezembro de 2019. 